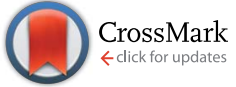

Cite this: RSC Adv., 2015, 5, 45703
Received 11th March 2015

Accepted 8th May 2015

DOI: $10.1039 / c 5 r a 04300 j$

www.rsc.org/advances

\section{Photoinduced self-assembly of carboxylic acid- terminated lamellar silsesquioxane: highly functional films for attaching and patterning amino-based ligands $\uparrow$}

\author{
Lingli Ni, ${ }^{\text {*ad }}$ Abraham Chemtob, ${ }^{\text {*a }}$ Céline Croutxé-Barghorn, ${ }^{a}$ Céline Dietlin, ${ }^{b}$ \\ Jocelyne Brendlé, ${ }^{\mathrm{b}}$ Séverinne Rigolet, ${ }^{\mathrm{b}}$ Loïc Vidal, ${ }^{\mathrm{b}}$ Alain Dieterlen, ${ }^{\mathrm{c}}$ Elie Maalouf ${ }^{\mathrm{c}}$ \\ and Olivier Haeberléc
}

\begin{abstract}
Recently, long $n$-alkyltrimethoxysilanes $\left(\mathrm{H}_{3} \mathrm{C}_{(}\left(\mathrm{CH}_{2}\right)_{n} \mathrm{Si}\left(\mathrm{OCH}_{3}\right)_{3}\right)$ have proven to self-assemble into mesoscopically ordered passive lamellar films through an efficient solvent-free photoacid-catalysed solgel process. By using an analogue precursor architecture presenting a terminal ester group $\left(\mathrm{H}_{3} \mathrm{COC}(\mathrm{O})\left(\mathrm{CH}_{2}\right)_{10} \mathrm{Si}\left(\mathrm{OCH}_{3}\right)_{3}\right)$, both functional and tuneable nanostructured organosilica films were synthesized, while keeping all the processing advantages of light-induced self-assembly. The subsequent attachment of a fluorescent amino-based ligand (Safranin O) was performed using a two-step procedure. The ester end groups were first hydrolysed in reactive carboxylic acid using standard methods, and activated with an amino ligand to form amide bonds. Hydrolysis and ligand coupling were assessed through infrared and solid-state ${ }^{1} \mathrm{H}$ NMR spectroscopy. Direct patterning of the fluorescent ligand-functionalized silsesquioxane film was performed by exposure to deep UV light under a mask to cause the local degradation of the dye. The resultant photopatterned film was detected using fluorescence microscopy. This UV method could represent an effective and general approach for attaching and patterning amino-based ligands, with less restriction on substrate and surface preparation than self-assembled monolayers.
\end{abstract}

\section{Introduction}

Hybrid sol-gel silicates derived from silsesquioxane precursors, $\mathrm{R}-\left[\mathrm{Si}\left(\mathrm{OR}^{\prime}\right)_{3}\right]_{n}(n \geq 1)$, where $\mathrm{R}$ and $\mathrm{OR}^{\prime}$ are respectively covalently attached organic groups and hydrolyzable alkoxy functions, represent a highly versatile class of nanocomposites. ${ }^{1,2}$ In the early development phase, the reported hybrids were amorphous, and their growth was essentially driven by the inexhaustible choice of organic moieties achieved through the Si-C bond molecular scale homogeneity. More recently, research efforts have centred on ways to inhibit the disordering effect of

${ }^{a}$ Laboratory of Photochemistry and Macromolecular Engineering, ENSCMu, University of Haute-Alsace, 3 bis rue Alfred Werner, 68093 Mulhouse Cedex, France. E-mail: abraham.chemtob@uha.fr; Fax: +33 38933 5017; Tel: +33 389335030

${ }^{b}$ Institute of Material Science of Mulhouse, CNRS, UMR 7361, University of HauteAlsace, 3 bis rue Alfred Werner, 68093 Mulhouse Cedex, France

${ }^{c}$ Laboratory of Modelling, Intelligence, Process and Systems, ENSISA, University of Haute-Alsace, 61 rue Albert Camus, 68093 Mulhouse Cedex, France

${ }^{d}$ Key Laboratory for Palygorskite Science and Applied Technology of Jiangsu Province, College of Bioengineering and Chemical Engineering, Huaiyin Institute of Technology, Huaian 223003, People's Republic of China. E-mail: nilingli520@126.com; Fax: +86 517 83559056; Tel: +86 51783559056

$\dagger$ Electronic supplementary information (ESI) available. See DOI: $10.1039 / \mathrm{c} 5 \mathrm{ra} 04300 \mathrm{j}$
$\mathrm{Si}-\mathrm{O}-\mathrm{Si}$ condensation, in order to create ordered organosilica nanostructures. ${ }^{3,4}$ Harnessing silsesquioxanes in a way that the organic and siloxane fragments self-assemble into spatially defined and organized nanodomains has been a very attractive goal to fabricate a wide spectrum of advanced hybrid nanomaterials including membranes, ${ }^{5}$ conductive films, ${ }^{6}$ absorbents $^{7}$ and optoelectronic devices. ${ }^{8}$ In fact, unique chemical or physical properties may emerge from hybrid materials when organic moieties form mesoscopically segregated functional domains, both ordered and confined. ${ }^{9}$

When the ultimate aim is not the fabrication of mesoporous materials, the major route for synthesizing nanostructured hybrids has been the direct template-free self-assembly of silsesquioxane precursors, usually leading to lamellar structures. Critical to self-organization is the presence of noncovalent binding organic groups (van der Waals forces, $\pi-\pi$ stacking) or/ and amphiphilic interactions. This has imposed strict constraints on precursor architecture and synthesis conditions, which account for the fact that the long-range molecular ordering of most organosilica hybrids has remained very challenging. ${ }^{10}$ Accordingly, self-assembled hybrids rely only on a handful of mono-, bis- or multi-silylated building blocks picked essentially for driving self-assembly. To this end, the suitable 
organic moieties R must be able to develop hydrophobic interactions (long hydrocarbon chain ${ }^{11}$ ) or/and hydrogen bonds (ureido, ${ }^{12}$ amide groups ${ }^{13}$ ). Notwithstanding the wealth of periodically ordered mesostructures achieved with these precursors, they have actually a narrow application potential due to restricted intrinsic functionality. For hybrids to fully benefit from nanostructuration, there is the need of simple organic groups, not only tolerant or favourable to self-assembly, but also able to confer functionality and specific properties to the final material. There have been very few examples of such 'active' nanostructured silsesquioxanes, containing for example photosensitive (azobenzene, ${ }^{14}$ diacetylene,${ }^{15}$ perylenediimide ${ }^{16}$ ) or conductive organic groups (crown ether, ${ }^{17}$ perylene ${ }^{18-20}$ ). Recently, Mehdi et al. reported several multi-step routes to yield amino-, thiol-, ${ }^{21}$ sulfonic acid-, ${ }^{21}$ carboxylic acid- ${ }^{22-25}$ and phosphonic acid- ${ }^{23}$ functionalized lamellar hybrids. The high density of reactive and accessible end groups arranged within a robust lamellar mesostructure was exploited for the chelation of transition metals and lanthanides in separation applications. ${ }^{3}$ Despite the success of this methodology, all the reported materials lacked uniform morphology control.

In this work, we report an efficient UV-driven approach to $\mathrm{COOH}$-functionalized lamellar organosilica films with longrange molecular ordering and uniform film morphology via a photoacid-catalysed sol-gel process. Using this original approach, we have recently described the formation of 'passive' lamellar alkyl silicate films ${ }^{26,27}$ and its mechanism. ${ }^{28} \mathrm{UV}$ control offers several advantages over conventional sol-gel process such as storable, ready-to-use formulation with no pot-life issue since the photocatalyst (superacid) is released on demand. Additionally, photopolymerization helps to make the process faster, solvent-free and energy-saving. Here, a similar UV-mediated methodology is exploited to synthesize, for the first time, functional multilayer silsesquioxane films.

Introduction of carboxylic acid groups into the supramolecular structure is based on a 2-step procedure, as outlined in Fig. 1. Scheme 1 shows the structure of the starting esterterminated trimethoxysilane precursor $1\left(\mathrm{H}_{3} \mathrm{COC}(\mathrm{O})\left(\mathrm{CH}_{2}\right)_{10^{-}}\right.$ $\left.\mathrm{Si}\left(\mathrm{OCH}_{3}\right)_{3}\right)$ derived from a purely aliphatic precursor $\left(\mathrm{H}_{3} \mathrm{C}\left(\mathrm{CH}_{2}\right)_{9} \mathrm{Si}\left(\mathrm{OCH}_{3}\right)_{3}, 2\right)$. Upon UV irradiation in the presence of photoacid generator (PAG, Scheme 1), this precursor film condenses into a mesoscopically ordered and cross-linked lamellar architecture. Hydrophobic interactions $\left(\mathrm{C}_{10} \mathrm{H}_{21}\right)$ combined with hydrogen bonds $\left(\mathrm{CH}_{2}-\mathrm{C}=\mathrm{O}, \mathrm{Si}-\mathrm{OH}\right)$ serve to self-assemble precursor $\mathbf{1}$. Subsequently, the terminal ester groups of this robust structure can be partially hydrolyzed into carboxylic acid groups without undermining the mesostructural order. In our case, we chose precursor 1 because of the high abundance of useful amino-based ligands in chemistry, which can be conjugated in high yield to the resultant carboxylic acid groups. To illustrate the usefulness of the method, we used Safranin O, a fluorescent amino ligand (L, Scheme 1) mimicking for example biologically relevant amino derivative ligands able to bind proteins or promote the adhesion of mammalian cells..$^{29,30}$ The first advantage of this prototype system is that ligand's retention and binding onto the lamellar hybrid mesostructure can be readily confirmed by

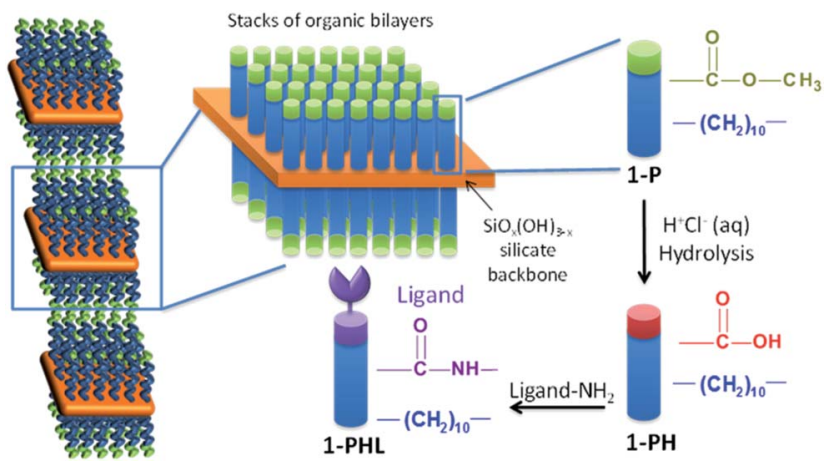

Fig. 1 Supramolecular structure formed by the photoinduced selfassembly of precursor 1

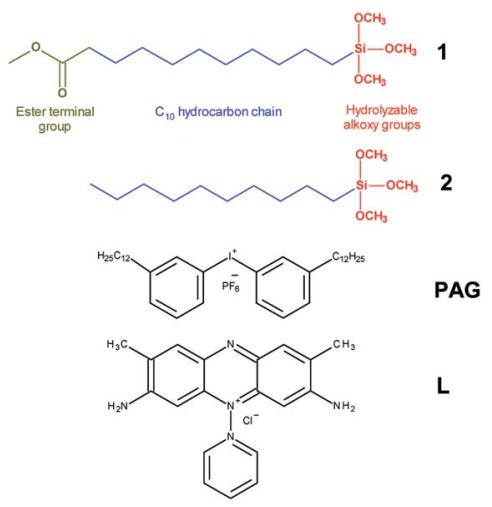

Scheme 1 Structures of monosilylated trimethoxysilane precursors (1, 2), photoacid generator (PAG) and fluorescent amino-based ligand (L).

optical and fluorescence imaging. Another key feature of $\mathbf{L}$ includes its facile spatially-controlled decomposition when exposed to deep UV light under a photomask, in order to generate precisely defined and easy characterized fluorescent patterns.

\section{Experimental section}

\subsection{Chemicals}

Methyl 11-(trimethoxysilyl)undecanoate (1, $95 \mathrm{~mol} \%), n$-decyltrimethoxysilane $(2,98 \mathrm{~mol} \%)$ were purchased from SIKÉMIA and ABCR, respectively. The bis-dodecyl diphenyliodonium hexafluoroantimonate salt (UV1241) PAG was provided by Deuteron. Hydrochloric acid (36.5-38 mol\%), acetonitrile ( 99.8 mol\%) and Safranin O (L, 85 mol\%) were supplied by SigmaAldrich. Technical acetone and ethanol were provided by Carlo Erba and VWR respectively. All the chemicals were used as received without further purification.

\subsection{Synthesis of ester- and carboxylic acid-functionalized silsesquioxane lamellar films}

$2 \mathrm{wt} \%$ of PAG was dissolved in precursor 1 to form a photolatent homogeneous mixture. The resultant nonhydrolysed solution was coated on a silicon wafer using an automatic film applicator 
(Elcometer 4340) equipped with a wire wound bar to yield a ca. 2 $\mu \mathrm{m}$ thick liquid film. Subsequent ambient UV irradiation was performed, at room temperature and ambient humidity (30$35 \%$ ), using a medium-pressure $\mathrm{Hg}$-Xe lamp (Hamamatsu L8252, $365 \mathrm{~nm}$ reflector) coupled with a flexible light-guide, at a controlled irradiance of $20 \mathrm{~mW} \mathrm{~cm}^{-2}$ (the emission spectrum of the UV lamp is provided in the ESI, Fig. S1 $\dagger$ ). The film samples were irradiated during $1800 \mathrm{~s}$ to yield transparent solid esterfunctionalized silsesquioxane film (1-P). The as-synthesized coated nanocomposite was immersed in an $\mathrm{HCl}$ aqueous solution $\left(50 \mathrm{~mL}, 2 \mathrm{~mol} \mathrm{~L}^{-1}\right)$ at $65{ }^{\circ} \mathrm{C}$ without stirring for $18 \mathrm{~h}$ to promote the conversion of the ester functions into carboxylic acids. The resultant film (1-PH) was thoroughly rinsed with deionized water until the $\mathrm{pH}$ of the washing solution remained within the range of 6 to 7. The as-synthesized film was dried overnight in vacuum at room temperature.

\subsection{Coupling of the carboxylic acid-functionalized silsesquioxane film with an amino fluorescent ligand and its deep UV photopatterning}

The substrate coated with acid-terminated silsesquioxane (1-PH) was activated by immersion in a solution of acetonitrile $(50 \mathrm{~mL})$ with Safranin O $\left(\mathbf{L}, 0.01 \mathrm{~mol} \mathrm{~L}^{-1}\right) .12 \mathrm{~h}$ exposure converted the transparent colourless film into a red film (1-PHL). Several washings of the film with acetonitrile were performed until the characteristic signature of Safranin O (maximum absorption at $\lambda_{\max }=517 \mathrm{~nm}$ ) became non detectable in UV-vis spectroscopy ( $1 \mathrm{~cm}$ thick quartz cell). The 1-PHL film was rinsed with deionized water and vacuum dried at room temperature for $24 \mathrm{~h}$. Subsequently, a TEM grid was deposited onto the solid film surface, and was eventually exposed during 1 hour to deep UV light provided by a medium-pressure $\mathrm{Hg}$-Xe lamp (Hamamatsu L8252, $254 \mathrm{~nm}$ reflector). This lamp was connected to a flexible light-guide generating a focused light beam on the film sample. Under these irradiation conditions, the flux of energetic photons is high enough (irradiance $=80 \mathrm{~mW} \mathrm{~cm}^{-2}$ for $\lambda<300$ $\mathrm{nm}$ and $600 \mathrm{~mW} \mathrm{~cm}{ }^{-2}$ for the whole UV spectrum) to enable the degradation of the organic ligand. Finally, the TEM grid was removed showing a red/transparent micropatterned film indicative of a spatially-controlled photodegradation. The sample was washed several times with ethanol and acetone to remove the organic fragments expelled from the film during photocalcination.

\subsection{Characterization}

Infrared spectra obtained by FTIR spectroscopy were recorded with a Bruker Vertex 70. The resolution of the infrared spectra was $2 \mathrm{~cm}^{-1}$. For all experiments, an effective precursor $1 \mathrm{film}$ thickness of $2 \mu \mathrm{m}$ was chosen and assessed by profilometry using an Altisurf 500 workstation (Altimet) equipped with a 350 $\mu \mathrm{m}$ AltiProbe optical sensor. X-Ray Diffraction patterns (XRD) were obtained on a PANalytical X'pert Pro diffractometer with fixed slits using $\mathrm{Cu} / \mathrm{K} \alpha$ radiation $(\lambda=1.5418 \AA)$ and $\theta-2 \theta$ mounting. Before analysis, films on silicon wafers were directly deposed on a stainless steel sample holder. Data were collected between 1 and $10^{\circ} 2 \theta$ degrees (XRD) with a scanning step of $0.01^{\circ} \mathrm{s}^{-1}$. Morphologies of the samples were characterized by scanning electron microscopy (SEM) (FEI Quanta 400 microscope working at $30 \mathrm{kV}$ ). The samples being nonconductive, they have been metalized with gold (15 nm thickness). ${ }^{1} \mathrm{H}(I=$ 1/2) MAS NMR experiment was performed at room temperature on a Bruker Avance II 400 spectrometer operating at $B_{0}=9.4 \mathrm{~T}$ (Larmor frequency $\nu_{0}=400.17 \mathrm{MHz}$ ). Single pulse experiment was recorded with a double channel $2.5 \mathrm{~mm}$ Bruker MAS probe, a spinning frequency of $25 \mathrm{kHz}$, a $\pi / 2$ pulse duration of $3.5 \mu \mathrm{s}$ and a 10 s recycling delay. 64 scans were recorded. Optical observations of the photopolymerized films were performed using an Olympus BX51 microscope in fluorescence modes. The microscope is equipped with U-LH75XEAPO Argon lamp. Fluorescence excitation is performed through a FITC block filter U-MWIBA2 with an excitation filter BP460-490, a dichroic mirror DM505 and an emission filter BA510-550. Observation was performed at low magnification using $40 \times \mathrm{NA}=0.65$ plan objectives, and at high magnification and high resolution using a $100 \times, \mathrm{NA}=1,4$ PlanApo oil-immersion objective. A CoolSnap $\mathrm{HO}^{2}$ cooled camera is used for recording images. For precise and repetitive sample positioning, a Märzhäuser Wetzlar SCAN $130 \times 852$-D motorized stage is used. Accurate specimen focusing as well as three-dimensional measurements can be performed via motorized focusing controlled by the homemade software developed on ImageJ platform. Image processing (stacking, intensity and dimensional measurements) has been performed using the ImageJ software.

\section{Results and discussion}

\subsection{Synthesis of self-assembled ester- and carboxylic acid- terminated silsesquioxane films}

1 and 2 are two monosilylated silsesquioxane precursors (Scheme 1) having in common one trimethoxysilyl group connected to a long $\mathrm{C}_{10}$ hydrocarbon chain. Such structural combination has recently proven to drive multilayer selfassembly through hydrophobic interactions. ${ }^{28}$ Additionally, 1 has a tuneable methyl methanoate group $\left(\mathrm{H}_{3} \mathrm{COC}(=\mathrm{O})-\right)$, thereby raising the question about the effect of this ester terminal group on supramolecular organization. Both precursors are commercially available, very stable in the open air and nonvolatile when they are in film form at ambient conditions. 1and 2-based liquid films containing $2 \mathrm{wt} \%$ of PAG were coated on silicon wafer substrate. Subsequent UV irradiation converted them into solid silsesquioxane films.

As shown in Fig. 2, the XRD pattern of the hybrid films 1-P and 2-P derived respectively from 1 and $\mathbf{2}$ reflect the formation of highly ordered mesostructures. Regardless of the precursor, the long hydrophobic organic chains favoured low curvature mesophases, and the formation of lamellar structures with an intense (001) reflection. Additionally in 1-P, the appearance of new (002) and (003) reflections (along with some peak narrowing) indicate a better ordering. This may be induced by additional hydrogen bonding between terminal $\mathrm{CH}_{2}-\mathrm{C}=\mathrm{O}$ moieties, which is the only structural difference between both precursors. Higher inter- and intramolecular interactions between organic groups can enhance the enthalpic association forces, and 
promote self-assembly. The corresponding $d_{100}$ values are equal to $3.58 \mathrm{~nm}$ for $\mathbf{1 - P}$ and $2.78 \mathrm{~nm}$ for $\mathbf{2 - P}$. These results are relatively consistent with the bilayer repeating unit distance $\mathrm{RSi}(\mathrm{OH})_{3-x} \mathrm{O}_{x} \cdots \mathrm{O}_{x}(\mathrm{OH})_{3-x} \mathrm{SiR}$ (1-P: $3.52 \mathrm{~nm}$ and 2-P: $3.14 \mathrm{~nm}$ ) predicted by molecular models (using ChemDraw 3D calculation). This result therefore confirms the head-to-head bilayer packing of the lamellae, schematically shown in Fig. 1. The film is made up of macroscopic multilayered crystallites with no specific orientation in contrast to Self-Assembled Monolayers (SAMs). Typically a few tens to a few hundreds of mesolayers may form spontaneously, but there was no estimate of the crystallite size. Furthermore, altering the aliphatic spacer with an ester end group has not affected the resulting mesophase. Accordingly, a longer hydrophobic pendant chain reduces the surfactant packing parameter, thus maintaining a lamellar organization in the film 2-P. The FTIR spectrum of the nanocomposite derived from 1 (see the ESI, Fig. S2 $\dagger$ ) shows a quantitative consumption of the band corresponding to methoxysilyl functions $\left(v_{\mathrm{s}}\left(\mathrm{SiOCH}_{3}\right) \approx 2840 \mathrm{~cm}^{-1}\right)$ within one minute. Moreover, based on the continuous growth of the Si-O-Si antisymmetric stretching band (1000-1260 $\left.\mathrm{cm}^{-1}\right)$, we infer that photoinduced condensation reactions take place. However, there is no sign of ester groups' hydrolysis because the band at $1740 \mathrm{~cm}^{-1}$ ( $v_{\text {asym }}$ of $\mathrm{C}=\mathrm{O}$ groups) is unchanged (position, intensity) during and even after UV exposure. As a highly efficient reaction, we suggest that the superacid-catalysed hydrolysis of methoxysilyl groups may proceed through the permeation of only traces of atmospheric water. ${ }^{31}$ Conversely, the acid-catalysed ester hydrolysis is an equilibrated reaction, which requires generally a much higher water concentration to shift the equilibrium towards products. Furthermore, the ester groups compartmentalized in the hydrophobic channel of the hybrid mesophases may not be accessible to the nucleophilic attack of water molecules, which on the contrary are localized preferentially in the hydrophilic siloxane interlayers.

However, heating the as-irradiated film 1-P at $65{ }^{\circ} \mathrm{C}$ in an acid $\mathrm{HCl}$ aqueous solution promotes the slow hydrolysis of the ester functions without damaging the aspect of the resultant

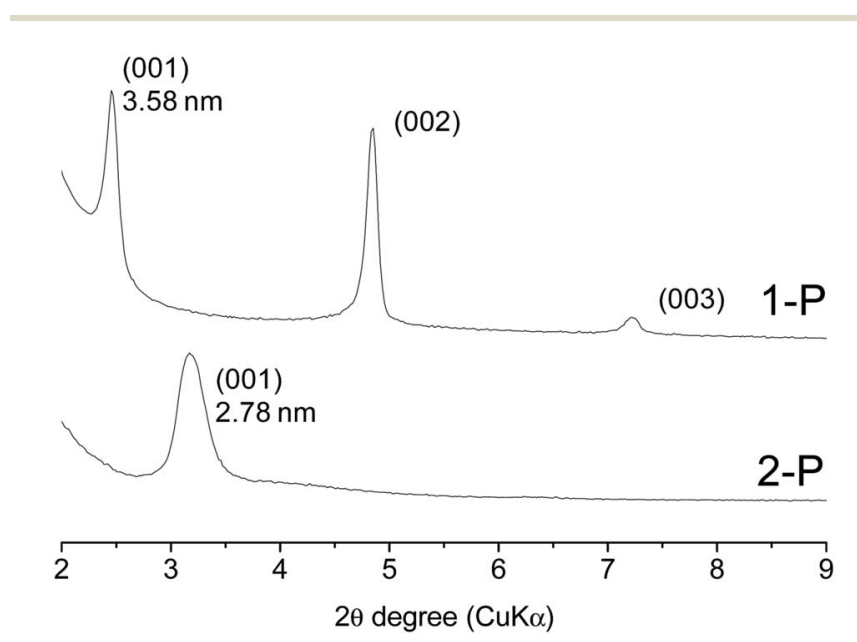

Fig. 2 XRD patterns for the two nanocomposite films (1-P and 2-P) assembled from 1 and 2 . film (1-PH). Fig. 3 shows the evolution of the IR spectrum in the carbonyl stretching region (1600-1800 $\mathrm{cm}^{-1}$ ) after $18 \mathrm{~h}$ immersion. We see a significant decrease of the band assigned to ester groups at $1740 \mathrm{~cm}^{-1}(\mathrm{C}=\mathrm{O}$ ester symmetric stretch) and the emergence of a neighbouring band at $1710 \mathrm{~cm}^{-1}$ reflecting the concomitant formation of hydrogen-bonded carboxylic acid groups $(\mathrm{C}=\mathrm{O}$ symmetric stretch of $\mathrm{COOH})$. Based on the relative integrated absorbance of these bands, we infer that the yield of hydrolysis is $c a$. $40 \%$. Comparison of the IR spectra of the films 1-P and 1-PH in the $\mathrm{CH}$ and $\mathrm{OH}$ stretching region (2800-3800 $\mathrm{cm}^{-1}$ ) shows that hydrocarbon chain remains unchanged, while there is no longer band corresponding to residual hydrogen-bonded silanols $\left(3400 \mathrm{~cm}^{-1}\right.$, stretch of the $\mathrm{OH}-\mathrm{O}$ bonds), thus indicating further siloxane acid-catalysed condensation. The formation of acid protons and their possible engagement in hydrogen-bonding was investigated by ${ }^{1} \mathrm{H}$ MAS NMR based on the proton chemical shift. As shown in Fig. 4, the spectrum of 1-PH exhibits a distinctive acidic proton signal at ca. $11.2 \mathrm{ppm}$, assigned to the $\mathrm{CO}_{2} \mathrm{H}$ protons, while absent before hydrolysis (1-P). ${ }^{32}$ This resonance is the clear signature of hydrogen-bonded $\mathrm{COOH}$ groups, but its broadness may also suggest mixture of different hydrogen-bonded structures and the possibility of some free $\mathrm{CO}_{2} \mathrm{H}$ groups (9 ppm). Furthermore, there is a relative decrease of the resonance attributed to the pendant methyl protons $\left(\mathrm{CH}_{3} \mathrm{O}\right)$ of the ester group, slightly shifted downfield from 3.4 to $3.7 \mathrm{ppm}$ after reaction. A hydrolysis degree of $c a$. $40 \%$ was estimated by comparing the 1-P and 1-PH spectra, which is consistent with FTIR data. The increase in siloxane condensation during the ester hydrolysis step is also noticeable in the ${ }^{1} \mathrm{H}$ spectrum through the complete disappearance of hydrogen bonded $\mathrm{SiOH}$ protons $(4.4 \mathrm{ppm}){ }^{33}$ The resonances of the aliphatic protons at $\sim 1$ to $2 \mathrm{ppm}$ in the hydrolysed film (1-PH) are notably broader than those of the ester-functionalized film (1-P). The larger line width of the methylene protons $\left(\mathrm{CH}_{2}\right)$ may reflect a more rigid local environment due to higher level of condensation or/and enhanced hydrogen-bonding interactions among the $\mathrm{COOH}$ end groups. In contrast to ester groups, the carboxylic acid

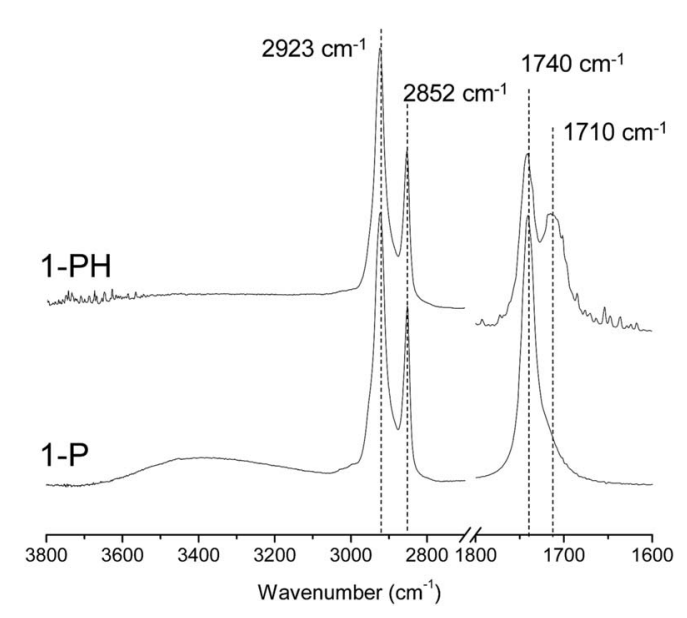

Fig. 3 FTIR spectra of the silsesquioxane films 1-P and 1-PH obtained after $18 \mathrm{~h}$ immersion time in a $2 \mathrm{~mol} \mathrm{~L}^{-1} \mathrm{HCl}$ aqueous solution at $65^{\circ} \mathrm{C}$. 
group can act as both a hydrogen-bond donor through the $\mathrm{C}-\mathrm{OH}$ groups and an acceptor via the $\mathrm{C}=\mathrm{O}$ oxygen, leading to a complex array of hydrogen bonds favoured by the head-to-head configuration of the lamellar mesostructure (Fig. 2). As a result, the chain mobility of the carboxylic acid terminated silsesquioxane may be quite restricted, and approach that of a rigid crystalline solid. TGA data (see ESI, Fig. S3†) confirm that 1-PH decomposes at higher temperature than 1-P, respectively 520 and $460{ }^{\circ} \mathrm{C}$ for a weight loss of $50 \%$. The presumed $\mathrm{H}$-bonded interactions engaged in the $\mathrm{COOH}$-terminated film could provide the nanocomposite with better thermal stability.

Fig. 5 shows the result of ester hydrolysis on the XRD pattern of the nanocomposite film assembled from 1, indicating clearly a conservation of the long-range ordered lamellar mesostructure. Nevertheless, hydrolysis caused a slight decrease in the $d_{001}$-spacing from 3.58 to $3.06 \mathrm{~nm}$ due to the end group shortening as well as the siloxane interlayer contraction induced by post-condensation reactions. Moreover, the exposure to a concentrated acid solution induced also greater disorder (one order of the $00 l$ peaks was almost lost) along with some peak

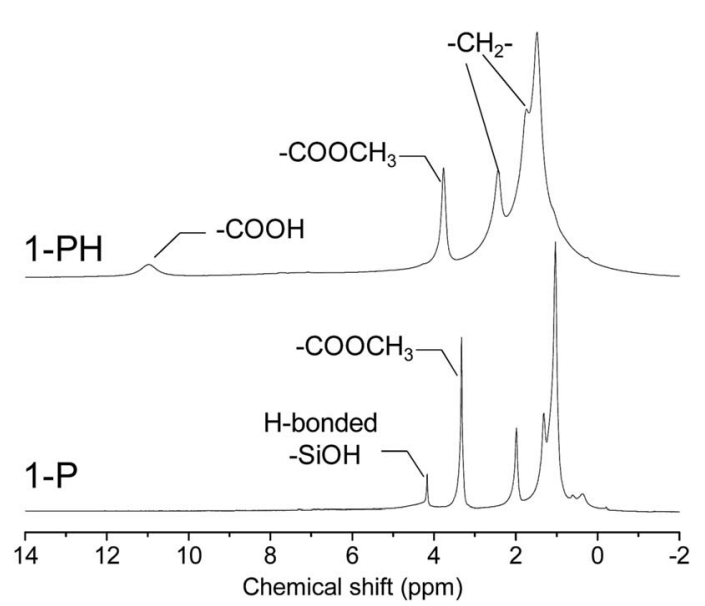

Fig. 4 Solid state ${ }^{1} \mathrm{H}$ MAS NMR spectra of the hybrid films 1-P and 1$\mathrm{PH}$ following ester hydrolysis.

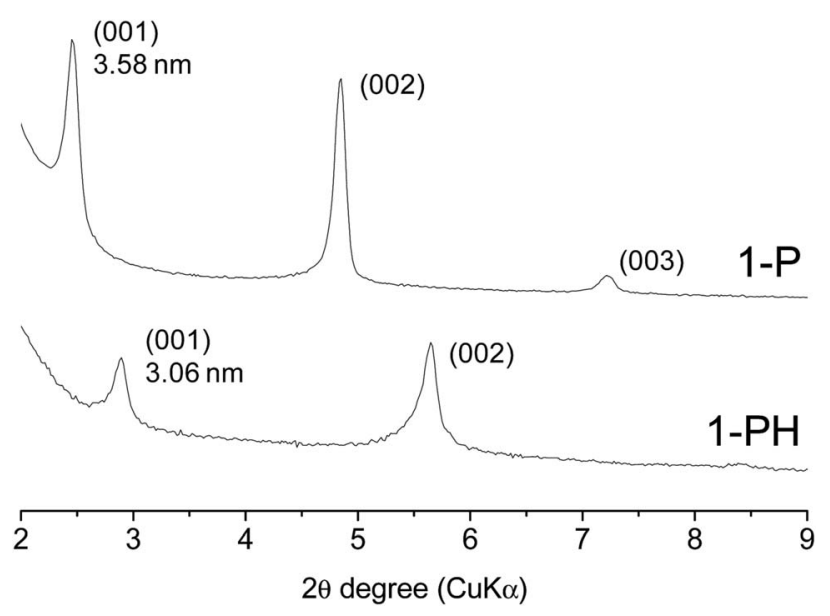

Fig. 5 XRD patterns of the silsesquioxane films 1-P (as-irradiated film derived from precursor 1) and 1-PH (after ester hydrolysis of film 1-P). broadening. Although hydrolysis could be enhanced by a prolonged exposure to $\mathrm{HCl}$ solution, these conditions clearly affect the mesostructure stability. The hydrolysis conditions were chosen to ensure a trade-off between conversion and ordering. The SEM images in Fig. 6 provide further evidence that the lamellar structure is retained. Even after the acid treatment, one can guess from the blurred images the same plate-like lamellar crystallites in the 1-P and 1-PH films.

\subsection{Fluorescent micropattern: direct patterning using deep UV}

The COOH-terminated silsesquioxane film (1-PH) represents a highly functional mesostructured support. Although accessibility
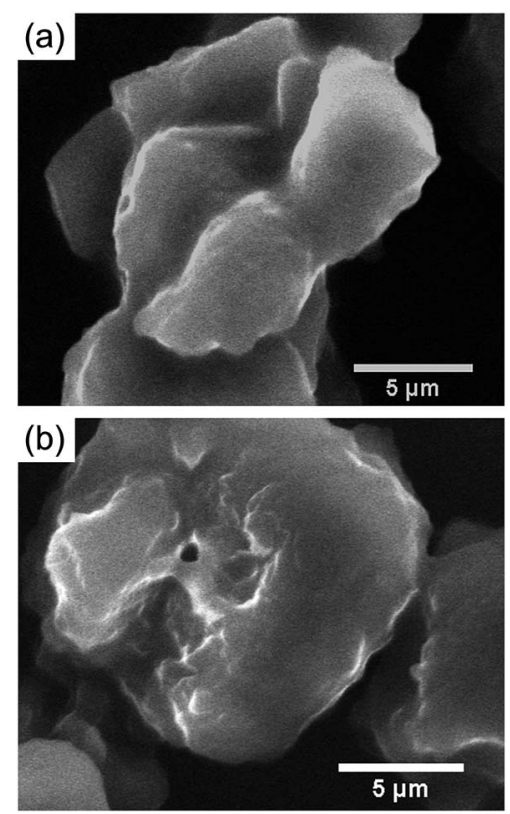

Fig. 6 Representative SEM images of the scratched nanocomposite films 1-P (a) and 1-PH (b).

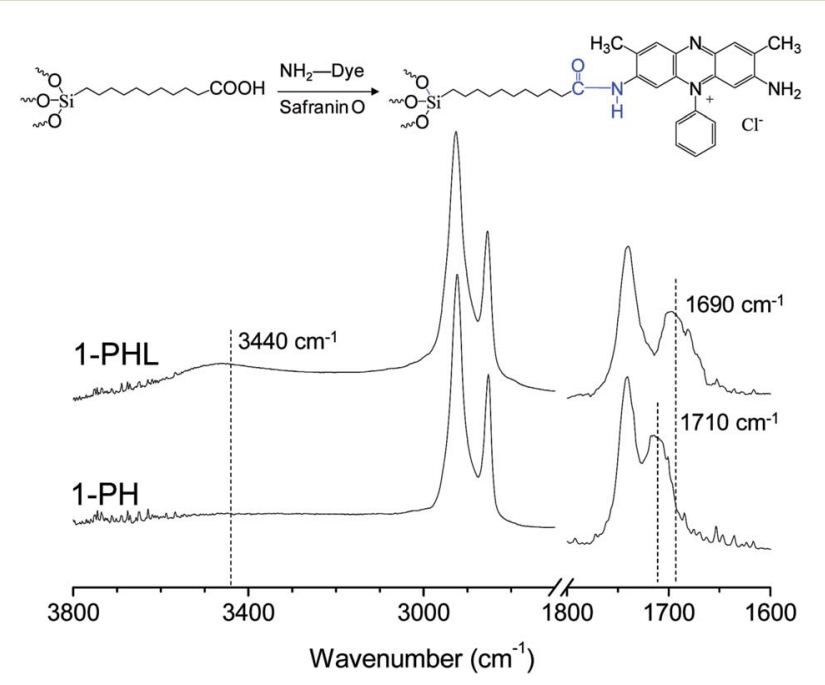

Fig. 7 FTIR spectra of the $\mathrm{COOH}$-functionalized hybrid film 1-PH and 1-PHL obtained after immersion in an ethanolic solution of $\mathrm{L}$. 
may be lower than in surface reaction using SAMs, the multilayer structure provides a higher density of reactive groups and an enhanced robustness due to siloxane cross-linking. The reactive carboxylic acid functional groups found in the hybrid film 1-PH allow it to be activated for attachment of amino ligands using standard method as that of 'normal' carboxylic acid group in organic chemistry. After immersion in a solution of a diamino fluorescent ligand (Safranin O, L), the resultant film (1-PHL) was washed several times with ethanol to remove the excess of dye non-specifically anchored to the silsesquioxane network. Binding was first detected straightforwardly by optical and fluorescence microscopy (data not given). Additionally, we used FTIR spectroscopy to assess the yield of coupling. Fig. 7 shows the IR spectra of the $\mathbf{C O O H}$-terminated hybrid to which the ligand $\mathbf{L}$ has been coupled. After activation, there is no band corresponding to residual carboxylic acid groups $(\mathrm{C}=\mathrm{O}$ symmetric stretch of $\mathrm{COOH}, \approx 1710 \mathrm{~cm}^{-1}$ ), which are replaced entirely by another blue-shifted band of similar intensity assigned to $\mathrm{NH}-\mathrm{C}(\mathrm{O})$ amide groups $\left(\mathrm{C}=\mathrm{O}\right.$ amide stretch $\left.\approx 1690 \mathrm{~cm}^{-1}\right),{ }^{33}$ thus suggesting a quantitative coupling. Another evidence was given by the appearance of the characteristic $v(\mathrm{~N}-\mathrm{H})$ band at $3440 \mathrm{~cm}^{-1}$. A benchmark experiment was performed by immersing a nonhydrolyzed film (1-P) in the same fluorescent ligand solution. As expected, the film remained transparent after washing and IR spectra revealed no sign of amide linkages or dye entrapment. We introduced finally a simple method to fabricate a fluorescent pattern based on the use of deep UV light directed through an optical mask deposited onto the 1-PHL film surface. We used energetic photons to promote the spatially-controlled degradation of the organic fragments of the hybrid film exposed to UV light. After irradiation, the film was washed several times with acetone and ethanol, and the pattern was studied by optical and fluorescent microscopy. Fig. 8 displays a series of optical images (a-d) of the patterned film prepared with masks of different shapes and sizes. The bright regions correspond to the irradiated areas, where the fluorescent and coloured ligand was degraded. In contrast, the red regions were masked and visibly preserved
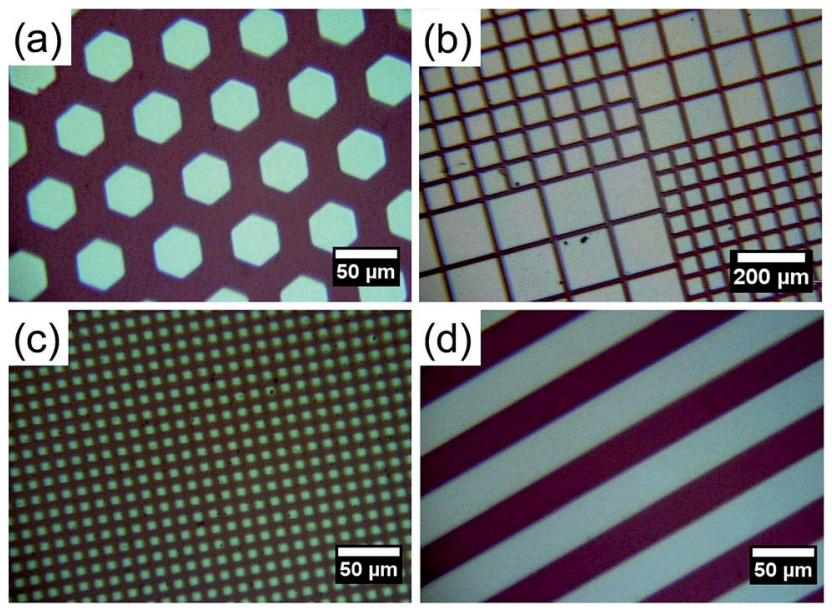

Fig. 8 Optical microscopy images of the patterned 1-PHL film obtained with different pattern feature size and shape: (a) hexagon; (b), mixed squares; (c), square; (d) bar (scale bar: 50 or $200 \mu \mathrm{m}$ ).
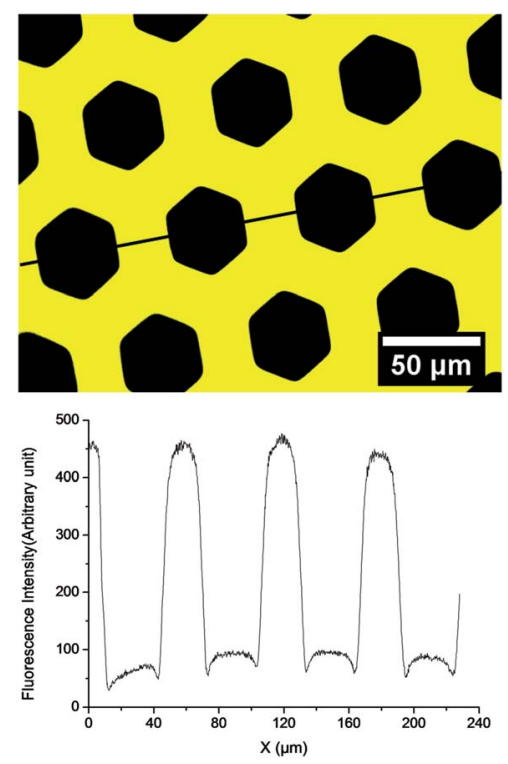

Fig. 9 Image of the photopatterned 1-PHL film surface obtained with fluorescence microscopy (scale bar $=50 \mu \mathrm{m}$ ).

from calcination. Obviously, this direct photopatterning method allows the generation of precisely defined patterns of any arbitrary shape. Highly resolved micropatterns are achieved, and the smallest features that we have resolved are squares with a $7.5 \mu \mathrm{m}$ side (Fig. 8c). The FTIR analysis (see ESI, Fig. S4†) of the irradiated areas reveals a complete cleavage of the amido bonds and a significant decrease of the $\mathrm{C}-\mathrm{H}$ stretching modes (2800 and 3100 $\mathrm{cm}^{-1}$ ) while the broad envelope $\left(1000-1300 \mathrm{~cm}^{-1}\right)$ assigned to $\mathrm{Si}-\mathrm{O}-\mathrm{Si}$ antisymmetric stretching modes is unchanged. This result emphasizes a selective and partial removal of the organic components of the hybrid film but sufficient to fully quench the fluorescence. The consequence is a decreased thickness of $c a$. $400 \mathrm{~nm}$ in the exposed areas and the formation of well-resolved wells as evidenced by atomic force microscopy (see ESI, Fig. S5 $\dagger$ ). Additionally, the photogenerated pattern was investigated by fluorescence microscopy. Fig. 9 shows the fluorescence emission image of the sample obtained with the hexagonalshaped mask (Fig. 8a). Clearly, the honeycomb was successfully replicated. The non-exposed areas (bright yellow regions) outside the hexagons emit strong and uniform fluorescence signal, demonstrating the capacity of this process to access micropatterned fluorescence. The surface patterning of fluorescence molecules has found already a great importance in displays, optical memory devices and molecular switches, as well as in the sensor and imaging industries. ${ }^{34-36}$

\section{Conclusions}

Carboxylic acid terminated monolayers have already demonstrated their potential as reactive surface in covalent immobilization of biomolecules, electrochemistry, and crystal growth. In this report, we have described a UV methodology to create $\mathrm{COOH}$-functionalized silsesquioxane films possessing a highly ordered multilayer mesostructure. The method required the 
photoacid-catalysed sol-gel process of ester-terminated alkoxysilane 1. Subsequent ester hydrolysis by $\mathrm{HCl}$ treatment allowed their conversion into carboxylic acid terminal groups as demonstrated by FTIR and solid state ${ }^{1} \mathrm{H}$ MAS NMR (yield: $40 \%$ ). A combination of XRD and SEM ensured that this chemical reaction was not accompanied by a loss of the initial mesostructure. The resultant $\mathrm{COOH}$-functionalized represented a suitable platform for quantitative coupling of amino ligands such as Safranin O. High quality fluorescence micropatterns were achieved using a UV degradation photolithography procedure.

By successfully adapting this technique to the immobilization and patterning of biologically active amino-reactive ligands for instance, there exists significant potential to study cell adhesion and spreading, biofouling mechanism, or the elaboration of bioanalytical devices (biosensors, protein biochips, miniaturization of DNA analyses)..$^{37,38}$ We believe that micrometer-scale ordered film structure have several advantages over molecular-scale monolayers based on chloro- or alkoxysilane including higher functionality, potential applicability on a variety of substrates without particular surface preparation and chemical/mechanical resistance because of the cross-linked siloxane interlayers.

\section{Notes and references}

1 C. Sanchez, P. Belleville, M. Popall and L. Nicole, Chem. Soc. Rev., 2011, 40, 696-753.

2 C. Sanchez, C. Boissière, S. Cassaignon, C. Chaneac, O. Durupthy, M. Faustini, D. Grosso, C. Laberty-Robert, L. Nicole, D. Portehault, F. Ribot, L. Rozes and C. Sassoye, Chem. Mater., 2014, 26, 221-238.

3 A. Mehdi, C. Reyé and R. J. P. Corriu, Chem. Soc. Rev., 2011, 40, 563-574.

4 S. Fujita and S. Inagaki, Chem. Mater., 2008, 20, 891-908.

5 M. Barboiu, Chem. Commun., 2010, 46, 7466-7476.

6 N. Mizoshita, T. Tani and S. Inagaki, Adv. Funct. Mater., 2011, 21, 3291-3296.

7 E. Besson, A. Mehdi, A. Van der Lee, H. Chollet, C. Reye, R. Guilard and R. J. P. Corriu, Chem.-Eur. J., 2010, 16, 10226-10233.

8 X. Sallenave, O. J. Dautel, G. Wantz, P. Valvin, J.-P. Lère-Porte and J. J. E. Moreau, Adv. Funct. Mater., 2009, 19, 404-410.

9 A. Chemtob, L. Ni, C. Croutxé-Barghorn and B. Boury, Chem.-Eur. J., 2014, 20, 1790-1806.

10 B. Boury and R. J. P. Corriu, Chem. Rec., 2003, 3, 120-132. 11 A. Shimojima and K. Kuroda, Chem. Rec., 2006, 6, 53-63.

12 J. J. E. Moreau, L. Vellutini, M. Wong Chi Man, C. Bied, J. L. Bantignies, P. Dieudonné and J. L. Sauvajol, J. Am. Chem. Soc., 2001, 123, 7957-7958.

13 S. C. Nunes, N. J. O. Silva, J. Hummer, R. A. S. Ferreira, P. Almeida, L. D. Carlos and V. De Zea Bermudez, RSC Adv., 2012, 2, 2087-2099.

14 N. Liu, K. Yu, B. Smarsly, D. R. Dunphy, Y.-B. Jiang and C. J. Brinker, J. Am. Chem. Soc., 2002, 124, 14540-14541.
15 H. Peng, J. Tang, J. Pang, D. Chen, L. Yang, H. S. Ashbaugh, C. J. Brinker, Z. Yang and Y. Lu, J. Am. Chem. Soc., 2005, 127, 12782-12783.

16 Y. Luo, J. Lin, H. Duan, J. Zhang and C. Lin, Chem. Mater., 2005, 17, 2234-2236.

17 M. Barboiu, S. Cerneaux, A. van der Lee and G. Vaughan, J. Am. Chem. Soc., 2004, 126, 3545-3550.

18 L. Yang, H. Peng, K. Huang, J. T. Mague, H. Li and Y. Lu, Adv. Funct. Mater., 2008, 18, 1526-1535.

19 J. Alauzun, A. Mehdi, C. Reye and R. J. P. Corriu, J. Am. Chem. Soc., 2005, 127, 11204-11205.

20 J. Alauzun, E. Besson, A. Mehdi, C. Reyé and R. J. P. Corriu, Chem. Mater., 2008, 20, 503-513.

21 J. Alauzun, A. Mehdi, C. Reyé and R. J. P. Corriu, Chem. Commun., 2006, 347-349.

22 R. Mouawia, A. Mehdi, C. Reyé and R. J. P. Corriu, J. Mater. Chem., 2007, 17, 616-618.

23 R. Mouawia, A. Mehdi, C. Reyé and R. J. P. Corriu, J. Mater. Chem., 2008, 18, 2028-2035.

24 J. H. El-Nakat, N. Al-Hakim, S. Habib, P. Obeid, M.-J. Zacca, G. Gracy, S. Clement and A. Mehdi, J. Inorg. Organomet. Polym. Mater., 2014, 24, 508-514.

25 A. Boullanger, G. Gracy, N. Bibent, S. Devautour-Vinot, S. Clément and A. Mehdi, Eur. J. Inorg. Chem., 2012, 2012, 143-150.

26 A. Chemtob, L. Ni, A. Demarest, C. Croutxé-Barghorn, L. Vidal, J. Brendlé and S. Rigolet, Langmuir, 2011, 27, 12621-12629.

27 L. Ni, A. Chemtob, C. Croutxé-Barghorn, L. Vidal, J. Brendlé and S. Rigolet, J. Mater. Chem., 2012, 22, 643-652.

28 L. Ni, A. Chemtob, C. Croutxé-Barghorn, J. Brendlé, L. Vidal and S. Rigolet, J. Phys. Chem. C, 2012, 116, 24320-24330.

29 J. Lahiri, E. Ostuni and G. M. Whitesides, Langmuir, 1999, 15, 2055-2060.

30 P. Jonkheijm, D. Weinrich, H. Schroder, C. M. Niemeyer and H. Waldmann, Angew. Chem., Int. Ed., 2008, 47, 9618-9647.

31 H. De Paz, A. Chemtob, C. Croutxé-Barghorn, S. Le Nouen and S. Rigolet, J. Phys. Chem. B, 2012, 116, 5260-5268.

32 S. Pawsey, M. McCormick, S. De Paul, R. Graf, Y. S. Lee, L. Reven and H. W. Spiess, J. Am. Chem. Soc., 2003, 125, 4174-4184.

33 J. B. D. delaCaillerie, M. R. Aimeur, Y. ElKortobi and A. P. Legrand, J. Colloid Interface Sci., 1997, 194, 434-439.

34 M. Irie, T. Fukaminato, T. Sasaki, N. Tamai and T. Kawai, Nature, 2002, 420, 759-760.

35 M. Melucci, M. Zambianchi, L. Favaretto, V. Palermo, E. Treossi, M. Montalti, S. Bonacchi and M. Cavallini, Chem. Commun., 2011, 47, 1689-1691.

36 S.-Y. Ku, K.-T. Wong and A. J. Bard, J. Am. Chem. Soc., 2008, 130, 2392-2393.

37 G. M. Whitesides, E. Ostuni, S. Takayama, X. Y. Jiang and D. E. Ingber, Annu. Rev. Biomed. Eng., 2001, 3, 335-373.

38 T. Ekblad and B. Liedberg, Curr. Opin. Colloid Interface Sci., 2010, 15, 499-509. 